\section{MS50-O4 History of Direct Methods: a personal account}

Davide Viterbo

1. Università del Piemonte Orientale, DISIT, viale T. Michel 11, Alessandria, Italy

email: davide.viterbo@uniupo.it

Having started my research in Crystallography in 1962, I could not live the birth of direct methods, but I had the invaluable chance of having accounts from many of the "founding fathers" (Figure 1).

My story will start from Harker and Kasper inequalities in 1948 as the first useful method to derive phases from measured intensities: in the same year they were applied by Gillis to solve a structure. Then in 1950 Karle and Hauptman generalized inequalities in a determinant form. In 1952 Sayre derived his famous equation and Okaya, Nitta and Zachariases proposed the use of symbols. In 1953 the monograph by Karle \& Hauptman introduced important concepts and the use of probability methods, further developed also by Cochran, Woolfson, Bertaut and Klug in the following years. In 1966-67 Isabella Karle, using symbolic addition, solved a non-centrosymmetric structure and triggered the growth of the use of DM, also thanks to the development of computing software and hardware. Then in 1968 Woolfson proposed the multisolution method and with his co-workers developed the very successful MULTAN program. In 1970-71 he organized the schools on "Direct and Patterson methods of solving crystal structures" in Parma and York, that opened the route to the schools in Erice in 1974.

The final part will consider the exceptional developments of DM up to the late 80's, thanks to the works by Beurskens, Hauptman, Giacovazzo, Main, Sheldirk, Schenk, Woolfson and their co-workers.
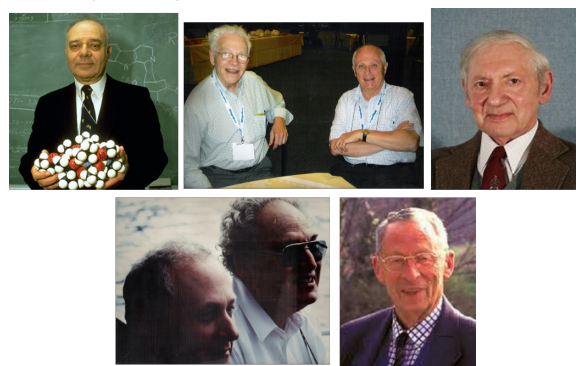

Figure 1. J. Karle, D. Sayre, M. Woolfson, , H. Hauptman, F Bertaut

\section{MS50-O5 The Artwork of Maurits C. Escher and Crystallography}

\author{
Henk Schenk
}

1. University of Amsterdam, The Netherlands

email: h.schenk@uva.nl

Maurits C. Escher (1898-1972) is one of the world's most famous graphic artists. He was also one of the few artists to lecture at an IUCr Congress - perhaps the only one. The scientific interest in Escher's work for crystallographers is based on his hobby of making drawings of regular divisions of the plane. Moreover, as crystallographers study objects in three dimensions, it might well be that the way in which Escher played with the third dimension in his graphic art is also a reason behind their appreciation of his work.

In 1936, Escher visited the Alhambra and was fascinated by the regularity of the mosaic patterns there. He sketched many of them in detail. This lead to his hobby of making original symmetrical drawings, but now with recognizable objects rather than ornaments, mostly animals. He used these periodic drawings (some of which are reproduced in part in the figure) as studies for making his woodcuts and other graphic art, even in one case a biscuit tin. For example, drawing No. 4 with puppets in three colours shows up in his woodcut Metamorphosis I (1937), woodcut Development 1 (also 1937) relates to drawings 14 and 15 , and his famous woodcut Day and Night (1938) is based on drawing 18. By 1940 his passion had resulted in 30 symmetrical drawings. He created a total of 137 of these patterns during his lifetime, and many of his other works are based on them.

Escher also developed 'a personal layman's theory on color symmetries'. His contact with crystallographers resulted in an exhibition at the Cambridge IUCr Congress in 1960, which gave Caroline MacGillavry the idea of collecting a group of patterns that could be of help in teaching plane-group symmetry. The Teaching and the Executive Committees of the International Union of Crystallography (IUCr) embraced this idea, as did Escher. Caroline selected 40 of the drawings to form the book. One plane group was not represented, so a pattern was specially created by Escher to fill the gap. This took place when Lodovico Riva and I were students in Caroline's group, so we met Escher himself. Caroline wrote texts to accompany each plate, and so the book Symmetry Aspects of $M$. C. Escher's Periodic Drawings was created and first published in 1965 . Over 60,000 copies of the book were sold, making it the most popular IUCr publication ever.

In the lecture the artwork of Escher will be presented, but the emphasis will be on the symmetrical drawings, their symmetry and colour symmetry. 